\title{
Calculation of harmonic losses and ampacity in low-voltage power cables when used for feeding large LED lighting loads
}

\author{
N. Milardovich ${ }^{1, *}$, L. Prevosto ${ }^{2}$ and M. A. Lara ${ }^{3}$ \\ ${ }^{1}$ Laboratorio de Electricidad, Departamento Ingeniería Electromecánica \\ Facultad Regional Venado Tuerto (UTN) Laprida 651 (2600), Venado Tuerto (Santa Fe), Argentina \\ ${ }^{2}$ Grupo de Descargas Eléctricas, Departamento Ingeniería Electromecánica \\ Facultad Regional Venado Tuerto (UTN) Laprida 651 (2600), Venado Tuerto (Santa Fe), Argentina \\ ${ }^{3}$ Facultad de Ciencias Exactas, Ing. y Agrimensura. Maestría en Energía para el Desarrollo Sostenible (UNR). Av. Pellegrini \\ 250 (2000), Rosario (Santa Fe), Argentina \\ *corresponding author, E-mail: nmilardovich@gmail.com
}

\begin{abstract}
A numerical investigation on the harmonic disturbances in low-voltage cables feeding large LED loads is reported. A frequency domain analysis on several commerciallyavailable LEDs was performed to investigate the signature of the harmonic current injected into the power system. Four-core cables and four single-core cable arrangements (three phases and neutral) of small, medium, and large conductor cross sections, with the neutral conductor cross section approximately equal to the half of the phase conductors, were examined. The cables were modelled by using electromagnetic finite-element analysis software. High harmonic power losses (up to 2.5 times the value corresponding to an undistorted current of the same rms value of the first harmonic of the LED current) were found. A generalized ampacity model was employed for re-rating the cables. It was found that the cross section of the neutral conductor plays an important role in the derating of the cable ampacity due to the presence of a high-level of triplen harmonics in the distorted current. The ampacity of the cables should be derated by about $40 \%$, almost independent of the conductor cross sections. The calculation have shown that an incoming widespread use of LED lamps in lighting could create significant additional harmonic losses in the supplying low-voltage lines, and thus more severe harmonic emission limits should be defined for LED lamps.
\end{abstract}

\section{Introduction}

With the technological advancement in semiconductors, light-emitting diode (LED) lamps are becoming in a promising lighting technology due to its superior energyefficiency and longer life-time compared to most of the conventional light sources $[1,2]$.

In general lighting applications, a compact ac/dc (alternating current/direct current) converter [3,4] should be used to supply dc current to LEDs, which introduce nonlinearity to the system. As nonlinear loads, LEDs might produce highly-distorted currents. These distorted currents are injected into the power system thus producing a large number of problems, such as additional power losses in conductors, which are dependent on the harmonic frequency [5]. The magnetic field generated by harmonic currents flowing in the conductor induces on the conductor itself eddy currents, which modify the current distribution displacing it toward the periphery; this "skin effect" phenomenon increases the value of the resistance (as compared to the dc resistance) in proportion to the root of the harmonic frequency, thus increasing the conductor power losses [6,7]. This same phenomenon can also be generated by the "proximity effect" due to currents flowing in nearby conductors which cannot be neglected when the distances of the nearby conductors are of the same order as the conductors radii $[6,7]$. These additional losses caused by harmonic currents must be accounted for by proper derating of the ampacity of the cable [6-8].

A large number of works were conducted on LEDs as an energy efficient lamp, but most of them have been devoted to the internal driver circuit design $[3,4]$. Several other works have concentrated on the light distribution and visual performance of LED lamps (e.g., [9]). A few contributions focused on harmonic emissions of LED lamps [10-11].

Although the input power of a single LED is quite low, an incoming widespread use of them in lighting could create significant additional harmonic losses in the existing lowvoltage lines. Since several national standards allow for the neutral conductor reduced sizing with respect to the phase conductors, many of these existing low-voltage installations have the cross section of the neutral conductor approximately equal to the half of the phase conductors.

This work investigates the harmonic disturbances in low-voltage installations having the neutral cross section approximately equal to half of the phase conductors when used for feeding large LED lighting loads. Four-core cables and four single-core cable arrangements (three phases and neutral) were examined. The cables were modelled by using the QuickField Lite, which is a commercially available 
electromagnetic finite-element manufactured by Tera Analysis Ltd.

analysis software

\section{LED harmonic signature}

The measured current waveform $(I)$ of a commercial LED ( 8 W Philips Master lamp) together with the applied voltage $(V)$ is shown in Fig. 1. As it can be seen, the current is highly-distorted. A frequency domain analysis of the current harmonics $\left(I_{p u}(h)\right)$ produced by several commerciallyavailable LEDs, is presented in Fig. 2. In this figure $I_{p u}(h)$ was expressed in per-unit of the fundamental current harmonic ( $h=1$ corresponding to a harmonic frequency of $f$ $=50 \mathrm{~Hz}$, being $h$ the order of the harmonic). The power and the commercial trade-mark of each examined LED were also indicated in Fig. 2. The experimental data can be approximately described by the power law

$$
\frac{I(h)}{I(1)}=h^{m} \text {, }
$$

being $m=-1.2 \pm 0.2$. The formula (1) was indicated by a solid line in Fig. 2. The relationship (1) defines the harmonic signature of the examined LED lamps. Note that the data corresponded to LEDs from 3 to $120 \mathrm{~W}$.

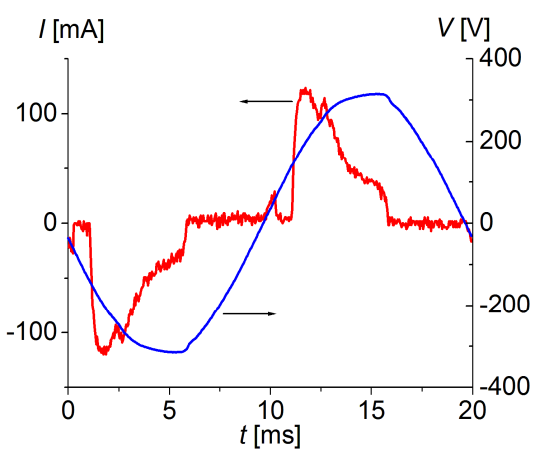

Figure 1: Current and voltage waveform of a (8 W) commercially-available LED lamp.

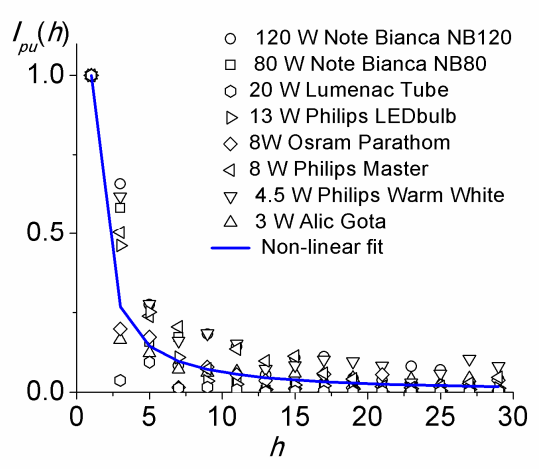

Figure 2: Frequency domain analysis of the current harmonics on several commercially-available LEDs. The blue line represents the power-law (1) with $m=1.2$.

A digital circuit monitor (Schneider Electric PowerLogic CM 4000) was used for the measurements presented in Figs. 1 and 2.

\section{Cable types and configurations}

Two different types of cables were examined. The first type was an arrangement of four single-core cables in contact with each other, as they were specified by IEC 60502-1 [12]. The schematic of the used cable arrangement is shown in Fig. 3, while its geometric dimensions are summarized in Table 1. As the conductors in all cables were assumed solid in the modelling, the conductor dimensions showed in Table 1 are slightly smaller than the actual dimensions. This assumption leads to results that are on the conservative side. Cases where the conductors were copper and the cross section of the neutral conductor was approximately equal to the half of the phase conductors were modelled.

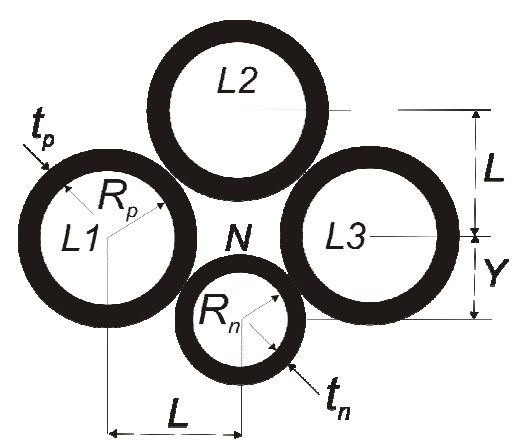

Figure 3: Layout of the examined single-core arrangement

The second type corresponded to four-core cables as they were specified by CENELEC Standard HD603 [13]. In this case, a large cross-section sector-shaped cable, namely, $3 \times 240+120 \mathrm{~mm}^{2}$; was examined.

Table 1: Dimensions of the modelled cable arrangement.

\begin{tabular}{|c|c|c|c|c|}
\hline \multirow[b]{2}{*}{ Dimensions $[\mathrm{mm}]$} & \multicolumn{4}{|c|}{ Nominal cable cross-section $\left[\mathrm{mm}^{2}\right]$} \\
\hline & $\begin{array}{l}0 \\
\stackrel{0}{1} \\
+ \\
n \\
\tilde{n} \\
x \\
m\end{array}$ & 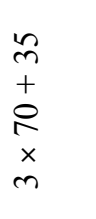 & $\begin{array}{l}\stackrel{P}{1} \\
+ \\
\stackrel{0}{ } \\
\stackrel{1}{x} \\
\times \\
m\end{array}$ & 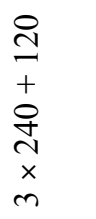 \\
\hline $\begin{array}{l}\text { Phase-conductor } \\
\text { radius, } R_{p}\end{array}$ & 3.3 & 4.7 & 6.2 & 8.8 \\
\hline $\begin{array}{l}\text { Neutral-conductor } \\
\text { radius, } R_{n}\end{array}$ & 2.3 & 3.3 & 4.7 & 6.2 \\
\hline $\begin{array}{l}\text { Thickness of phase- } \\
\text { conductor insulation, } \\
t_{p}\end{array}$ & 2.6 & 2.8 & 3.1 & 4.0 \\
\hline $\begin{array}{l}\text { Thickness of neutral- } \\
\text { conductor insulation, } \\
t_{n}\end{array}$ & 2.4 & 2.6 & 2.8 & 3.1 \\
\hline Distance $L$ & 8.4 & 10.6 & 13.1 & 18.0 \\
\hline Distance $Y$ & 6.5 & 8.2 & 10.5 & 12.7 \\
\hline
\end{tabular}

\section{Electromagnetic model}

In a conductor where the conductivity is sufficiently high, the displacement current density can be neglected, and the conduction current density is given by the product of the electric field and the electrical conductivity (ohm's law). With these simplifications, the Maxwell's equations are 


$$
\begin{gathered}
\nabla \times\left(\frac{\bar{B}}{\mu}\right)=\sigma \bar{E}, \\
\nabla \times \bar{E}=-\frac{\partial \bar{B}}{\partial t},
\end{gathered}
$$

where $\bar{B}$ is the magnetic field, $\mu$ is the magnetic permeability, $\sigma$ is the conductor electrical conductivity, and $\bar{E}$ is the electric field. Introducing the magnetic vector potential $\bar{A}(\bar{B} \equiv \nabla \times \bar{A})$ in (3), $\bar{E}$ can be expressed as

$$
\bar{E}=-\nabla V-\frac{\partial \bar{A}}{\partial t}
$$

(being $V$ the electrostatic potential) and (2) becomes

$$
\nabla \times\left[\frac{\nabla \times \bar{A}}{\mu}\right]=-\sigma \nabla V-\sigma \frac{\partial \bar{A}}{\partial t} .
$$

The electromagnetic software solved the diffusion equation (5) to obtain the spatial distribution of the total current density ( $\bar{J}$ ) over each conductor's surface $(S)$, having as input the measurable current in the conductor [14]

$$
\begin{gathered}
I=\int \bar{J} \cdot d \bar{S}=\int\left(\bar{J}_{0}+\bar{J}_{e d d y}\right) \cdot d \bar{S} \\
=\frac{V}{R_{d c}}-\sigma \int \frac{\partial \bar{A}}{\partial t} \cdot d \bar{S}
\end{gathered}
$$

where $I$ is the total current, and $R_{d c}$ is the dc conductor resistance. ( $\bar{J}_{0}$ is the spatial-average current density generated by potential electric fields, while $\bar{J}_{\text {eddy }}$ is the (eddy) current density induced by rotational fields). The Equation (6) assumed a uniform electrical conductivity over the conductor surface. This is justified because simple estimates showed that the temperature variations over the conductor's surface, due to the non-uniform distribution of the joule heat caused by the skin and proximity effects, are very small because of the large value of the thermal conductivity. For instance, in order of magnitude, the temperature variation $(\Delta T)$ along the diffusion length $\Lambda$, is given by

$$
\Delta T \approx \frac{\Lambda^{2}}{\kappa} \sigma E^{2}
$$

(being $\kappa$ the conductor thermal conductivity) which is much less than $1 \mathrm{~K}$ for a circular copper conductor $(\Lambda \equiv R / 2.4$, being $R \sim \mathrm{cm}$, its radius) with a joule heat density of about $10^{5} \mathrm{~W} / \mathrm{m}^{3}$.

At each harmonic frequency, the software calculates the losses per-unit length in each conductor using the integral

$$
P(h)=\frac{1}{\sigma} \int J(h)^{2} d S,
$$

where $P(h)$ is the harmonic losses per unit conductor length and $J(h)$ is the current density corresponding to the harmonic of order $h$.

\section{Simulation parameters}

The cables were modelled in two dimensions assuming that at each harmonic frequency, balanced, three-phase, and sinusoidal currents flow through them. The three-phase conductors were assumed carrying the following currents

$$
\begin{gathered}
I_{L 1}=I_{p} \cos \left(2 \pi h f t+\varphi_{h}\right), \\
I_{L 2}=I_{p} \cos \left(2 \pi h f t-h \frac{2}{3} \pi+\varphi_{h}\right), \\
I_{L 3}=I_{p} \cos \left(2 \pi h f t+h \frac{2}{3} \pi+\varphi_{h}\right),
\end{gathered}
$$

being $I_{p}$ the current peak value, $\varphi_{h}$ the angle phase of the harmonic order $h$, and $L 1, L 2$ and $L 3$ the three phases.

For nontriplen harmonic $(h \neq 3 N$, with $N=1,2,3, \ldots)$ the neutral conductor only carries the eddy currents calculated by the software. Notice that in this case, $h=3 \mathrm{~N}+$ 1 represents the direct sequence harmonics while $h=3 N-1$ represents inverse sequence harmonics. For triplen harmonics the current in the neutral conductor was assumed as

$$
I_{N}=3 I_{p} \cos (2 \pi h f t+\pi) .
$$

In order to obtain an accurate distribution of the current density over the conductor sections, it was checked that the size of the local numerical mesh was less than half the characteristic skin penetration length

$$
\delta \equiv \sqrt{\frac{1}{\sigma \mu \pi h f}},
$$

for each harmonic order. The study domain for the case of a sector-shaped cable, showing the non-uniform numerical grid (with up to about 4000 mesh cells) is presented in Figure 4 . At the boundary of the domain (at a radius up to 10 times the cable size) it was assumed that $\bar{A}=0$ because the magnetic field vanishes at a large distance (as compared to the cable size) from the cable.

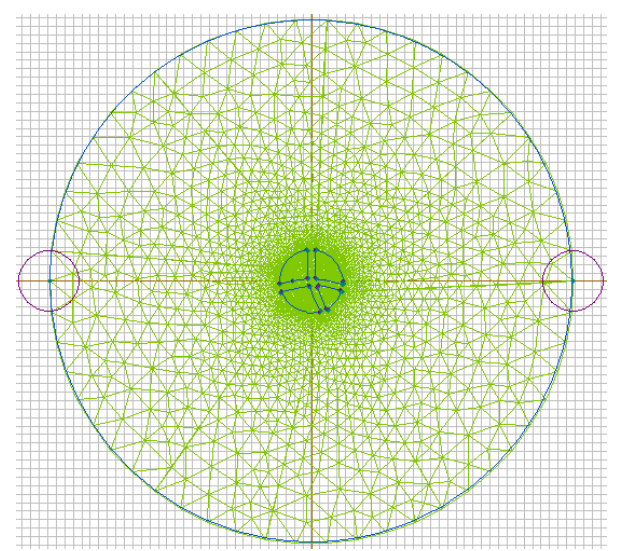

Figure 4: Non-uniform numerical grid generated by the software for the case of a four-core sector-shaped cable.

The simulations results presented in Section 6 were obtained for $\mu=4 \pi \times 10^{-7} \mathrm{H} / \mathrm{m}$ (non magnetic material was 
considered). The copper electrical conductivity at $20^{\circ} \mathrm{C}$ was taken as $\sigma=5.8 \times 10^{7} \Omega^{-1} \mathrm{~m}^{-1}$ according to IEC 60028 [15]. The $\sigma$ value was correspondingly corrected for other cable operating temperatures.

\section{Simulation results and discussion}

Figure 5 illustrates the spatial distribution of the root-meansquare (rms) value of the total current density over the conductors of cables of large and small sections, submitted to fifth-order $(h=5)$ harmonic current. The magnetic field lines produced by the current are also shown.
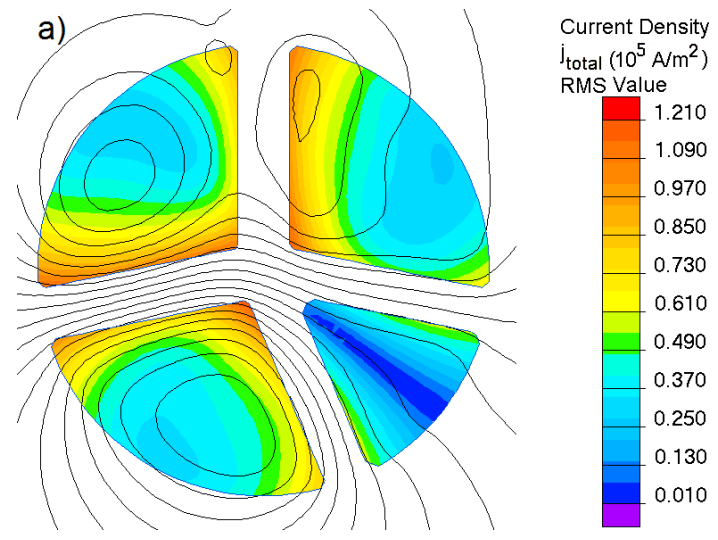

b)

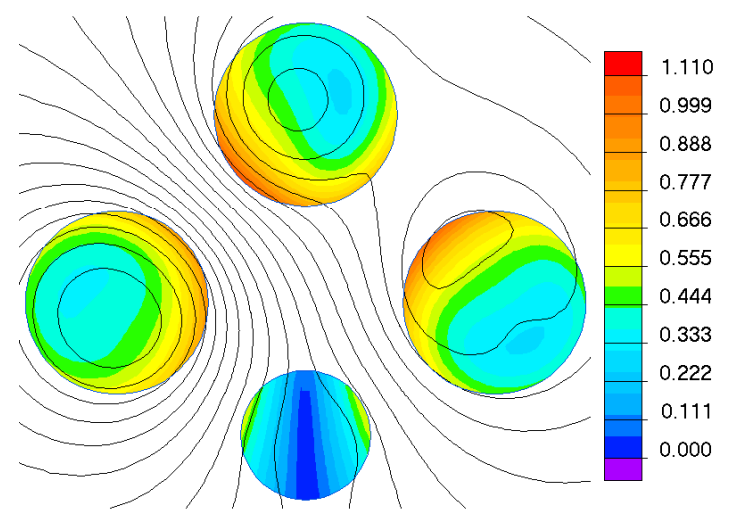

c)

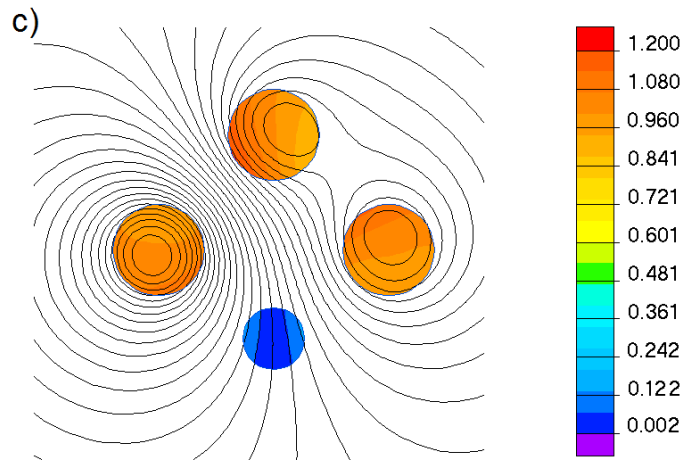

Figure 5: Spatial distribution of the rms current density for the fifth-order $(h=5)$ harmonic in a sector-shaped cable of 3 $\left.\times 240+120 \mathrm{~mm}^{2}, \mathrm{a}\right)$; and in four single-core cables, $3 \times 240$ $\left.+120 \mathrm{~mm}^{2}, \mathrm{~b}\right)$ and $\left.3 \times 35+16 \mathrm{~mm}^{2}, \mathrm{c}\right)$.

Fig. 5 a) corresponds to a $3 \times 240+120 \mathrm{~mm}^{2}$ sectorshaped cable, while Fig. 5 b) corresponds to an arrangement of four single-core cables $\left(3 \times 240+120 \mathrm{~mm}^{2}\right)$. In both cases the fifth-order harmonic current was $15 \mathrm{~A}$ (peak value). A noticeable reduction in the effective area of current circulation due to the skin and proximity effects is observed in both cases (although a more marked distortion on the current density seems to appear for the sector-shaped cable); thus causing a considerable increase of the ac conductor resistance, $R_{a c}$, (as compared to the dc resistance, $R_{d c}$ ), which in turn results in high-heat losses. Figure $5 \mathrm{c}$ ) corresponds to an arrangement of four single-core cables (3 $\times 35+16 \mathrm{~mm}^{2}$ ). In this case the fifth-order harmonic current was $5 \mathrm{~A}$. As is observed, the influence of the eddy currents is very small and the current density over the conductors is almost not distorted.

To calculate the $R_{a c}$ conductor resistance, an ac steadystate harmonic analysis was employed. Only the odd harmonics, up to the 29th, were considered. A higher value of this upper-limit did not appreciable impact the obtained results. Due to the geometry of the cables, the losses in the phase conductors are not identical. In fact, the losses in phase conductors $L 1$ and $L 3$ (Fig. 3) are the same, but, those in $L 2$ are different. The losses per-unit length in the threephase conductors, when a symmetrical current of rms value $I_{r m s}(h)$ and of frequency $f h$ flows through them, can be defined as $P_{L 1}(h), P_{L 2}(h)$, and $P_{L 3}(h)$; for $L 1, \mathrm{~L} 2$ and $L 3$, respectively. The uneven heat generation inside the cable is a fact that also needs to be considered when calculating the derating of cable ampacity. According to [16], the average cable temperature but also the temperature at any point along the insulation of the cable should not exceed the maximum permissible one. Therefore, for derating of the cable ampacity, the maximum conductor losses should be considered and not their average. For nontriplen harmonic ( $h$ $\neq 3 \mathrm{~N}$ ) the neutral conductor only carries the eddy currents calculated by the software, so the maximum cable losses can be represented by an effective conductor resistance per unitlength $R_{\text {eff }}(h)$ for the harmonic order $h$, which was defined as

$$
3 P_{L \max }(h)+P_{N}(h) \equiv 3 I_{r m s}^{2}(h) R_{e f f}(h),
$$

where

$$
P_{L \max }(h) \equiv \max \left\{P_{L 1}(h), P_{L 2}(h), P_{L 3}(h)\right\} .
$$

When triplen harmonics are present, the neutral conductor picks up current. An effective resistance, that reflects the maximum losses of the phase conductors ( $\widetilde{R}_{\text {eff }}(h)$ ), and another resistance $\left(R_{a c N}(h)\right)$ that reflects the losses of the neutral conductor, were defines as

$$
\begin{gathered}
3 P_{L \max }(h) \equiv 3 I_{r m s}{ }^{2}(h) \widetilde{R}_{e f f}(h), \\
P_{N}(h) \equiv I_{r m s N}{ }^{2}(h) R_{a c N}(h),
\end{gathered}
$$

where

$$
I_{r m s N}(h) \equiv 3 I_{r m s}(h),
$$

is the neutral conductor current for the harmonic current of order $h$. The resistances $R_{\text {eff }}(h)$ and $\widetilde{R}_{\text {eff }}(h)$, will be referred, from now on, as $R_{a c}(h)$. For comparative purposes 
Fig. 6 shows the ratio $R_{a c}(h) / R_{d c}$ of the phase conductors of the cables described in Table 1 and for a $3 \times 240+120$ $\mathrm{mm}^{2}$ four-core cable. As expected, the ratio increases with both frequency and conductor cross section due to skin and proximity effects. The curve is not smooth but presents spikes at triplen harmonics. This is mainly due to the increased losses in conductors $L 1$ and $L 3$ when zerosequence currents flow in the phase conductors and thereby in the neutral.

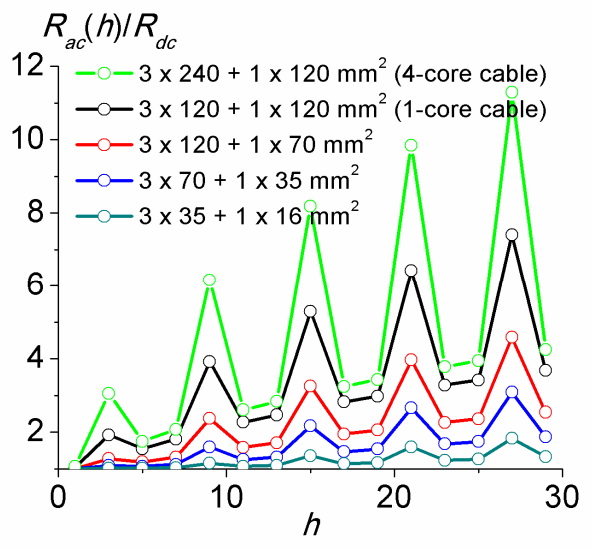

Figure 6: Variation with the harmonic order of the ratio $R_{a c}(h) / R_{d c}$ of the phase conductors of various examined cables.

Figure 7 shows the ratio for the neutral conductor of the cables analyzed in Fig. 6. The ratio is shown only for triplen harmonics, because only when triplen harmonics are present the neutral conductor picks up current (other than eddy currents). It is evident from Fig. 6 and 7 that the ratio of the neutral conductor is much smaller than that of the respective phase conductors. This occurs because the zero-sequence currents decrease the proximity effect significantly on the neutral conductor when its position, relative to the phase conductors, is as shown in Fig. 3.

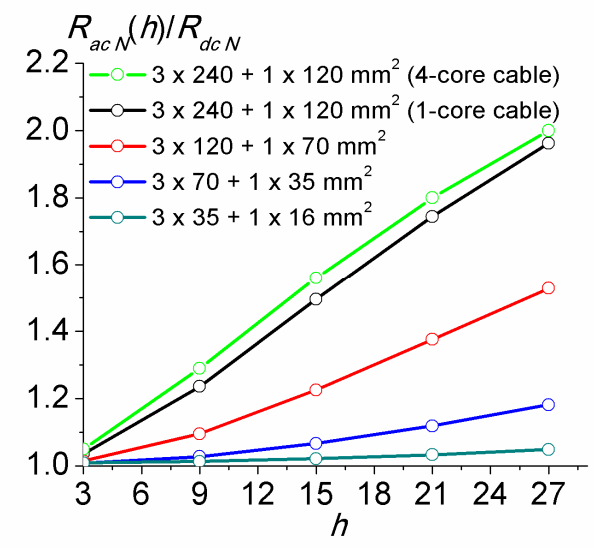

Figure 7: Variation with the harmonic order of the ratio $R_{a c N}(h) / R_{d c N}$ of the neutral conductor of various examined cables.

The simulation results corresponded to a conductor operating temperature of $70{ }^{\circ} \mathrm{C}$, which is the maximum conductor temperature for $\mathrm{PVC}$-insulated cables according to IEC 60502-1 [12]. It was checked that large variations in this temperature value (in the range 10 to $70^{\circ} \mathrm{C}$ ) only render slightly variations (less than $10 \%$ ) in the conductor resistance ratio).

The results of the employed electromagnetic model were validated by comparison to: a) the numerical model developed in [7], and b) the formulae given in the standard IEC 60287-1-1 [17] for 3 single-core cables arrangements. The differences in the calculated ratios $R_{a c}(h) / R_{d c}$ were in both cases less than $3 \%$ in the whole considered frequency range.

The cable losses can be approximately calculated by the following formula

$$
P_{l o s s}=3 \sum_{h=1}^{29} I_{r m s}^{2}(h) R_{a c}(h)+\sum_{h=3 N}^{27}\left(3 I_{r m s}(h)\right)^{2} R_{a c N}(h),
$$

where the first term on the right hand side represents the losses in the phase conductors, and the second term is the losses in the neutral conductor. This second term is present only when triplen harmonics are considered (i.e., $h=3,9$, $15,21,29)$. The values of $R_{a c}(h)$ and $R_{a c N}(h)$ were shown in Figs. 6 and 7.

It is important to compare the above calculated cable losses (17) with the losses produced in an identical cable but carrying an undistorted electric current of a rms value of $I_{r m s}(1)$. To do this, the cable losses ratio defined as

$$
\xi \equiv \frac{P_{l o s s}}{3 I_{r m s}^{2}(1) R_{a c}(1)},
$$

was calculated by using the harmonic signature given by (1) for the cables described in Table 1 and for a $3 \times 240+120$ $\mathrm{mm}^{2}$ four-core cable as was specified by CENELEC Standard HD603 [13]. The results obtained for the upperbound of $m(=-1.0)$ are shown in Table 2. The assumption on the $m$ value leads to results that are on the conservative side.

Table 2: Calculated cable losses ratio $\xi$ of various examined

\begin{tabular}{|c|c|c|}
\hline Cable type & $\begin{array}{l}\text { Nominal cable } \\
\text { cross-section }\left[\mathrm{mm}^{2}\right]\end{array}$ & $\xi$ \\
\hline \multirow{4}{*}{$\begin{array}{l}\text { Arrangement of } \\
4 \text { single-core } \\
\text { cable }\end{array}$} & $3 \times 35+16$ & 2.1 \\
\hline & $3 \times 70+35$ & 2.1 \\
\hline & $3 \times 120+70$ & 2.0 \\
\hline & $3 \times 240+120$ & 2.3 \\
\hline 4-core cable & $3 \times 240+120$ & 2.5 \\
\hline
\end{tabular}
PVC-insulated low-voltage cables feeding LED-type loads.

As is observed in Table 2, for a four-core cable with a cross-section of $3 \times 240+120 \mathrm{~mm}^{2}$, the power losses reaches 2.5 times the value corresponding to an undistorted current of the same rms value of the first harmonic of the LED current. Even for cables with relatively small cross sections, such as $3 \times 35+16 \mathrm{~mm}^{2}$, this ratio reaches about 2.1. Furthermore, if the skin and proximity effects are neglected in the cable losses (17) (the conductor radius is small as compared to the characteristic skin penetration length and the distances of the nearby conductors are large 
as compared to the conductor radius) and thus $\xi$ is not dependent on the cable cross-section; the losses ratio still reaches 2.0 for $m=-1.0$. The increase in the losses is mainly owing to the harmonic content of the distorted current.

As shown Table 2, large LED-like loads generate huge harmonic losses resulting in additional conductor heating. This heating will result in a higher temperature rise of the cable which can exceed its rated temperature; thus requiring the derating of the cable ampacity. By the way, it should be noted that the results of Table 2 are slightly lower than the actual losses ratio values due to the raise of the conductor resistance with the temperature.

When significant zero-sequence harmonic currents are present in the neutral, it becomes in an additional heat generating conductor and must be considered in the ampacity calculation. In such a case, the usual approximation for derating the cable ampacity [6,7] should be not accurate enough, because it only ensures that the phase conductors does not exceeds the maximum safe value, but the neutral should be overheating. The model developed in [18] should be employed instead, for re-rating the cable. In accordance to this model, the following matrix equations must be solved for the conductor temperatures to obtain the cable ampacity

$$
\left[\begin{array}{l}
P_{l o s s, 1}+\frac{T_{a}}{R_{1 a}} \\
P_{l o s s, 2}+\frac{T_{a}}{R_{2 a}} \\
P_{l o s s, 3}+\frac{T_{a}}{R_{3 a}} \\
P_{\text {loss }, 4}+\frac{T_{a}}{R_{4 a}}
\end{array}\right]=\left[\begin{array}{cccc}
\frac{1}{R_{11}} & \frac{-1}{R_{12}} & \frac{-1}{R_{13}} & \frac{-1}{R_{14}} \\
\frac{-1}{R_{21}} & \frac{1}{R_{22}} & \frac{-1}{R_{23}} & \frac{-1}{R_{24}} \\
\frac{-1}{R_{31}} & \frac{-1}{R_{32}} & \frac{1}{R_{33}} & \frac{-1}{R_{34}} \\
\frac{-1}{R_{41}} & \frac{-1}{R_{42}} & \frac{-1}{R_{43}} & \frac{1}{R_{44}}
\end{array}\right] \bullet\left[\begin{array}{c}
T_{1} \\
T_{2} \\
T_{3} \\
T_{4}
\end{array}\right],
$$

here, indices 1, 2, 3, 4 and 5 are attributed to phase conductors $L 1, L 2$ and $L 3$, to the neutral conductor, and to the surrounding environment; respectively. $T_{\alpha}$ is the temperature of the medium $\alpha(=1-5)$. For the computation of the thermal resistances $R_{i j}$, the Eqs. (17) to (23) in [18] and Eq. (42A) in [19] were employed assuming a cable suspended in still air $\left(T_{a}=40{ }^{\circ} \mathrm{C}\right)$ and a contact angle between conductors of 0.35 radians. The Eq. (19) was solved for the cables described in Table 1 by assuming a distorted current with a harmonic signature given by (1) (for $m=-1.0$ ) and for $I_{r m s}(1) \equiv I_{1} k$; being $I_{l}$ the maximum safe value of the undistorted current under the considered conditions (i.e., the cable rated-current) and $k$ the derating factor. The derating factor varies in the range $0<k \leq 1$, a unity derating factor means that no derating of the cable's ampacity is needed. For each examined cable the derating factor $k$ was obtained such that the temperature of any conductor of the cable did not exceed $70{ }^{\circ} \mathrm{C}$. The results were summarized in Table 3.

To check the accuracy of (19), the ampacities of five arrangements of 3 single-core cables $(3 \times 35,3 \times 50,3 \times 70$, $3 \times 120$, and $3 \times 240 \mathrm{~mm}^{2}$ ) in contacting each other, and in air; were compared to the ampacities given in the standard
IEC 60364-5-523:1999. The maximum difference was within $\pm 3 \%$.

Table 3: Calculated derating factor $k$ for PVC-insulated lowvoltage cables as described in Table 1 feeding large LEDlike loads.

\begin{tabular}{lll}
\hline \hline Cable type & $\begin{array}{l}\text { Nominal cable } \\
\text { cross-section }\left[\mathrm{mm}^{2}\right]\end{array}$ & $k$ \\
\hline \begin{tabular}{l} 
Arrangement of $\begin{array}{l}3 \times 35+16 \\
\text { 4 single-core } \\
\text { cable }\end{array}$ \\
\cline { 2 - 3 }
\end{tabular} & $3 \times 70+35$ & 0.60 \\
\cline { 2 - 3 } & $3 \times 120+70$ & 0.59 \\
\hline
\end{tabular}

The results showed that in all the examined cables the neutral conductor resulted severely overloaded due to the presence of significant zero-sequence harmonics in the distorted current. As is observed in Table 3, the ampacity of the cables should be derated by about $40 \%$; almost independent of the conductor cross sections. The derating decreases to $34 \%$ for a cable of $3 \times 120+70 \mathrm{~mm}^{2}$ because in such a case the neutral size is larger than half of the phase conductors.

It should be noted that for the examined lamps having an active input power $\leq 25 \mathrm{~W}$, the third harmonic current does not exceed the limit established by the IEC 61000-3-2 Standard [20]; which assesses the harmonic emission limits for lighting equipments. Hence, in accordance with the present results, this criterion should be more severe considering an incoming widespread use of LED lamps in lighting.

\section{Conclusions}

Calculation of harmonic disturbances in existing lowvoltage installations having the neutral cross section approximately equal to half of the phase conductors when used for feeding large LED lighting loads was reported. The cables were modelled by using electromagnetic finiteelement analysis software. A generalized ampacity model was employed. Four-core cables and four single-core cable arrangements (three phases and neutral) of small, medium, and large conductor cross sections were examined. This study has shown that:

(1). The derating of the cable ampacity resulted about $40 \%$, almost independent of the conductor cross sections. If the derating is not accomplished, very high power losses up to 2.5 times the value corresponding to an undistorted current of the same rms value of the first harmonic of the LED current, were found.

(2). The cross section of the neutral conductor plays an important role in the harmonic losses, and thus in the derating of the cable ampacity, due to the presence of a high-level of triplen harmonics in the distorted current.

(3). An incoming widespread use of LED lamps in lighting could create significant additional harmonic losses in the supplying low-voltage lines, and thus more severely harmonic emission limits should be defined for LED lamps. 


\section{Acknowledgements}

L. P. is a member of the CONICET. N. M. and L. P. acknowledge financial support by Universidad Tecnológica Nacional, Facultad Regional Venado Tuerto.

\section{References}

[1] I. L. Azevedo, M. G. Morgan, F. Morgan, The transition to solid-state lighting, Proc. IEEE 97: 481$510,2009$.

[2] S. Chong-Tan, General $n$-Level Driving Approach for Improving Electrical-to-Optical Energy-Conversion Efficiency of Fast-Response Saturable Lighting Devices, IEEE Trans. Ind. Electron. 57: 1342-1353, 2010.

[3] W. Chen, S. Y. Ron Hui, Elimination of an Electrolytic Capacitor in AC/DC Light-Emitting Diode (LED) Driver With High Input Power Factor and Constant Output Current, IEEE Trans. Power Electron. 27: 1598-1607, 2012.

[4] X. Qu, S. C. Wong, C. K. Tse, Resonance assisted buck converter for offline driving of power LED replacement lamps, IEEE Trans.Power Electron. 26: 532-540, 2011.

[5] J. J. M. Desmet, I. Sweertvaegher, G. Vanalme, K. Stockman, R. J. M. Belmans, Analysis of the neutral conductor current in a three-phase supplied network with nonlinear single-phase loads, IEEE Trans. Ind. Appl. 39: 587-593, 2003.

[6] A. P. S. Meliopoulos, M. A. Martin Jr., Calculation of Secondary Cable Losses and Ampacity in the Presence of Harmonics, IEEE Trans. Power Delivery 7: 451-459, 1992.

[7] C. Demoulias, D. P. Labridis, P. S. Dokopoulos, K. Gouramanis, Ampacity of Low-Voltage Power Cables Under Nonsinusoidal Currents, IEEE Trans. Power Delivery 22: 584-594, 2007.

[8] A. Hiranandani, Calculation of cable ampacities including the effects of harmonics, IEEE Trans. Industry Applicat.4: 42-51, 1998.

[9] S. Muthu, F.J. Schuunnans and M. Pashley, Red, green, and blue LEDs for white light illumination, IEEE J. Quantum Electron. 8: 333-338, 2002.

[10] S. Uddin, H. Shareef; A. Mohamed; M. A. Hannan, An Analysis of Harmonic Diversity Factors Applied to LED Lamps, Proc. POWERCON12, Auckland, New Zealand, pp. 1-5, 2012.

[11] V. Cuk, J.F.G. Cobben, W.L. Kling, R.B. Timens, An Analysis of Diversity Factors applied to Harmonic Emission Limits for Energy Saving Lamps, ICHQP10, Bergamo, Italy, pp. 1-6, 2010.

[12] Cables for rated voltages of $1 \mathrm{kV}$, IEC 60502-1: 2004 (E).

[13]Distribution cables of rated voltage 0,6/1 $\mathrm{kV}$, CENELEC Std. HD603 S1:1994/A2: 2003 E.

[14] QuickField Lite User Guide, Tera Analysis Ltd., 2014.

[15] International standard of resistance for copper, IEC 60028 Ed. 2.0 B: 1925.

[16] Electrical Installations of Buildings-Part 5: Selection and Election of Electrical Equipment-Section 523:
Current-Carrying Capacities in Wiring Systems, CENELEC Std. HD384.5.523, 2001, S2. Iec 60287.

[17] Electric cables-Calculation of the current rating, IEC 60287-1-1, CEI/IEC 60287-1-1:2006.

[18] A. Hiranandani, Calculation of conductor temperatures and ampacities of cable systems using a generalized finite difference model, IEEE Power Delivery.6: 15-24, 1991.

[19] J. H. Neher, M. H. McGrath, The Calculation of the Temperature Rise and Load Capability of Cable Systems, AIEE Transactions. 76: 752-772, 1957.

[20] Limits for harmonic current emissions (equipment input current $\leq 16$ A per phase), IEC 61000-3-2 Ed. 3.2 200904 . 